\title{
Media Education in Conditions of Visual Turn: European and Russian Experience
}

\author{
Konstantin Kiuru*, and Svetlana Simakova \\ Chelyabinsk State University; Journalism and Mass Communications Department, 454001, Chelyabinsk, Russia
}

\begin{abstract}
The present article covers the study of changing of approaches to media education in the conditions of visual turn. The most relevant problems are: preparation of a human to adequate perception and processing of information flow; increasing of audience's critical thinking; teaching a human different methods of working with information; perfecting of self-development skills in the conditions of media system that become more complicated. Certain changes have occurred in media consumption in the recent years: modern audience prefers visual content. Therefore, it is necessary to change the model of media education. The present article justifies the importance of the semiotic model of media education. Documents relating to problems of studying of the experience of formation and modern development of media education in Europe and in Russia, and documentation provided by educational institutions have become the material for the present study. The trends in media education stipulated by visual turn have been pointed out.
\end{abstract}

\section{Introduction}

Contradictions in development of media sphere give birth to multiple discussions, sharp judgments and contradictory opinions among theoreticians and practitioners of media sphere. However, thesis concerning the increasing role of information in private life as well as in public spheres (politics, economics, culture) has become an axiom long time ago. Statements of the most respected scientists of mass media sphere support this idea. For example: V. F. Oleshko confirms "Today one cannot perform effective management of any process and make the best solutions without full objective information relating to these aspects" [1]. A. P. Korochenskiy states "mass media have become the most important and powerful factor of functioning of different institutions, creating informational and cultural environment of our contemporaries" [2]. S. G. Korkonosenko holds to the same opinion. Developing the ideas of his colleagues and stating the fact that information is constantly strengthening its role, he comes to the conclusion that mass media also has stated to play more important role. From his point of view, "for modern man $<\ldots>$ mass media have become a usual environment" [3].

And this is true. Mass media have taken the largest part of human's leisure time. For example: According to the data of PlanetaSMI for 2015, a professional Internet magazine on media market, a common American spends 12 hours and 4 minutes in media sphere on daily basis. Here, in Russia we have the same situation. Summarizing the results of the second quarter of 2016 the cumulative daily average volume of media consumption in our country amounts to 630 minutes (excluding cross consumption). A modern man receives the largest part of information about the environment he lives in from mass media or so called mass communication media (the term of national science that is considered to be a synonym to English term "media"). Based on the information received a man makes his choice in different spheres of his life, forms his belief system, world views, and himself, forms moral and ethical basis, undergoes different levels of socialization etc.

Therefore we can conclude that contemporary world is totally mediatized. It means that it is formed and performed by media means, and first of all its central element - mass media.

New informational civilization formed by the industry of media means and mass media demands a modern man to make a transition to a new level interaction with information. Now the most essential issues are: the necessity of preparing a man for comprehension and processing of informational flow, the increasing of the level of critical thinking (for example: in order to identify political manipulative influence from media, government relations etc.), teaching a man methods of working with information, development of self-perfecting skills in the conditions of media system that becomes more and more complicated etc. It means that it is necessary to prepare a person for effective and safe living in the system of new informational conditions.

Media education as an up-to-date direction of contemporary pedagogics is able to solve these problems. This term comprises "a wide range of educational activities that help to discover and self-organize a person in the conditions of informational society. They manifest themselves in recognized media behavior based on

* Corresponding author: kkiuru@mail.ru 
humanistic ideals and values" [4]. We believe that this very definition is the most appropriate to draw your attention to humanistic message of media education and media pedagogics which are supposed to assist in developing of a person's successive realization in life, occupation, hobby and creative sphere.

However the above mentioned definition needs to be specified. That is why we give the definition of media education given by A. V. Fedorov, the most famous investigator and practitioner. He writes in one of his manuals "We consider media education as a process of a person's development on the basis and with the help of mass media (media means) with the purpose of forming cultural ways of communication with media, creative, communicational abilities, critical thinking, abilities of adequate comprehension, interpretation, analysis and evaluation of media texts, teaching of different forms of self-expression with the help of media means. Media competence helps a person to use the possibilities of media space of TY, radio, video, cinema, press, Internet and to understand the language of media culture" [5].

Therefore, media education is connected with all kinds of media and gives the possibility to understand the mechanisms of functioning of mass communication (the most important is the mechanism of intermediation between a person, society and government), gives a chance to master skills of development and self-perfection on the basis of knowledge received from media and mass media, helps to develop a person that is able to careful processing of media information (as an ideal - to creation of media texts) and to apply information about media in everyday life (as the case may be). A. V. Onkovich says that media education "is supposed to form culture of communication, the ability to comprehend, critically think and interpret media texts for the purpose of extension of general, social and cultural and professional knowledge, communicative and creative abilities" [6].

Media education has become a very popular definition in the recent years among professionals. Conferences held on this topic that gather teaching staff from all the postSoviet Union territory, publishing of special periodical publications (Mediaobrazovaniye (Mediaeducation) magazine is among them), the defense of theses devoted to this topic and publication of monographs, scientific articles and other scientific works witness the rising interest to this sphere. Different grant projects and also widely supported in this sphere.

However we should not but mention that in spite of the fact that the definition "media education" was formulated in 1973 during joint meeting of Informational Sector of UNESKO and International Council on Cinema and Television, media education in Russia has a long 100-year history. I. A. Fateeva [7] calls Higher Institute of photography and photo technics and cinema school (now called The All-Russian state institute of cinematography of S. A. Gerasimov (VGIK) established in Moscow in 1919 as the first harbingers of media education in our country. At this stage, in the 20th of the 20th century media education manifests itself in different formats cinema clubs, amateur cinema and photo studios, young journalists' clubs. Wall newspapers and cinema lessons became a part of reality of Soviet epoch.
But many of these initiatives in this sphere were suppressed when totalitarian rule had come to power. Media education was revived only at the end of 50th 60th of the XX century due to the thaw in political relations and fast development of television. In the 90th Russian TV experimented with so-called practical media education. Particularly, the first all-Russia channel showed a short program "School news". The program was prepared by teenagers - they developed ideas for a next program, worked out screen stories and worked as front men and cutters.

The 21 st century has brought positive changes to the media education. By the beginning of the XXI century, the media landscape significantly changes, Internet developed very fast; a wide range of higher and secondary educational institution relating to media sphere appeared. In 2002 the Ministry of Education of the Russian Federation registered officially specialty of higher educational institutions 03.13.30 «Media education». And a number of pedagogical institutions of higher education started teaching students according to this educational program [7].

Therefore the educational discipline has received its official recognition. The necessity of media education was acknowledged at the governmental level, which resulted to receiving by a man of high level of media competence (media literacy). We can not but mention that purpose of media educational activity can be formulated in different ways, for example: media literacy, media competence, media informational literacy, media erudition, media culture etc. No doubt that these definitions have a bit different meaning. However we are not going to concentrate on these shades of meaning in our work, that is why we regard them as terms that are very close in meaning, but the dominating definition will be media competence that stirs up less disputes in the recent years. This is a complex and multi aspect task that requires solution not only on the level of educational institutions of higher education, but also on the pre-school and school period of children's education and post-graduate stage. But the best solution is to achieve a high level of media competence for the whole life.

We should remember that the level of formation of media competence can be also different. It depends on a subject of media educational activity. University, school, club under creativity center or children's editorial office in a newspaper etc. - all these media educational agents possess different possibilities relating to the education of a man, because they fulfil different tasks and work with audience of different competence. But taken as a whole they form a net of educational institutions for media education. And due co-ordination between these educational institutions is able to give a perfect basis for formation of media competence skills among people of all ages.

\section{Materials and method}

Studies published in open sources and documents relating to the issues of development of contemporary media education in Europe and in Russia, as well as 
documentation from educational institutions (curricula) have become the material for this study. Analysis let us point out trends in organization of the system of media education in the conditions of visual turn.

\section{Discussion}

We can imagine the system of media education as media education of professionals and media education of teachers; as a part of general education (autonomous or integrated) and as special activity of institutions of additional education and leisure centers and finally as a continuous self- media education.

Asa result the system of media education should form a man possessing a high level of media competence, strong ability to comprehension, analysis, evaluation and creation of media texts, understanding of social, cultural and political conditions of mass media in modern world, code and representative systems used by media [8].

The last element becomes more and more important in the conditions of visual turn that supposes the overpass of science to studying of reality. In digital media sphere visual codes and representative systems of mass media become the main elements. It changes the content of contemporary media education - media education should focus on visual codes and grammar of media text (teach to understand the visual language of mass media). Semiotic model of media education based of works of R. Bart, U. Eko and other structuralists becomes more relevant. The leading pedagogical strategy in this model becomes teaching of decoration of media text, description of its content, associations, denotations and connotations.

U. Eko writes, "Code is a structure represented as a model and acting like a main rule when forming a certain message which become to be rendered grace to the code. All the codes can be compared on the basis of general code that is more simple and general" [9].

Another important pedagogical strategy is the ability to use different forms of visual language to create own media texts, creating different narrative structures in a media text. According to U. Eko's opinion, a traditional society is divided into people who generate culture and those who consume culture; those who write books and those who read them. Internet changes everything. The epoch of self-publishing has come: anybody can write anything winning the attention of a large number of readers. And this is wonderful.

A. V. Fedorov notices that the semiotic model has not been demanded in Russia for a long period of time [5]. But the reality has changed and this makes us to pay attention and use this model.

Let us address to the analysis of European experience of media education and let's see how they organized the studying of media language. The document "The resolution of European Parliament on media competence in the world of digital technologies" says that "media education must become an integral part of educational program at each stage of school education", it is necessary "to include media competence as the ninth basic competence in the European program of life-time education" (The resolution of European Parliament, 2008: 18-19).

Great Britain if one of the key figures in the sphere of media education in Europe. G. V. Mikhaleva remarks that "the contemporary British system of media education can be characterized as a humanistic and democratic" [10]. Mass media education (media education among all stratums of population) is realized in the form of formally integrated education as an obligatory component of some compulsory educational disciplines (language art, artistic disciplines) as well as an autonomous education via elective disciplines.

The British Film Institute supports studying of visual materials (films, TV, video) in schools. This is one of the key trends of contemporary media education that demonstrates visual turn in media consumption.

The analysis of the system of media education in Germany also demonstrates that a lot of time is paid to the studying of media language. Creative works based on images, audio and visual media press, multimedia are widely used in schools as an integrated media education.

The traditions of studying of visual language of media in France have long history connected with research of cinema language. This has resulted in introduction of a special discipline "Art of cinema" in the system of secondary and higher education, creation of special direction "Cinema and audio and visual arts" in the system of secondary school, introduction of program "Cinema and audio and visual arts" of licence level in the system of higher education. Now secondary and higher educational institutions address to this aspect of media language.

Media education in Hungary has evolved from cinema education. Initially the studying of aesthetics was integrated in the course of Hungarian language and literature. Later a special discipline on media education was introduced in the curricula of secondary educational institutions. Special courses on media education are represented in many universities of Hungary, for example: University of Budapest.

The discipline "Media competence" is studied in many schools of Romania. The discipline "Informational environment" is studied in many schools of Estonia. The system of higher education allows teaching of competent specialists for media. The analysis of curriculum of Bachelor program "Media communications" of Tallinn University gives us the possibility to conclude that great attention is paid to studying of the language of visual media (disciplines "Cinematographic recording", "Multi media", "Digital photo", "Visual communication", "Visual basis of composition", "Semiotics of multimedia" etc.).

In Russia we have a very interesting experience of Moscow State Pedagogical University named after M. Sholokhov. Different disciplines whether directly or indirectly relating to the visual media language ("Digital ecology", "Manipulating technologies of mass media", "Implementation and presentation of research activity", "Digital competence") are practiced as a part of Master's degree educational programs "Journalism. Media education" and "Journalism. Media and informational competence". 


\section{Results}

In our previous works we asked "Who and how must teach the young generation on the fundamentals of media competence?". However this is still no official decision. The problem of training of specialists is being solves mostly locally, on the level on universities, by means of introducing educational programs "Media teacher" or through integration into traditional educational disciplines / introduction a special discipline into curricula.

The faculty of journalism of Chelyabinsk State University possesses vast experience and significant results in the sphere of media education. The activity is being implemented in two directions - by means of system of additional education and by means of organization of special educational disciplines for students who study at "Journalism", "Philology, specialization "National philology (Russian language and literature)". For example: students who study journalism according to the Master's degree program study the discipline "Up-to-date technologies of media education". Those students who study journalism according to the Bachelor's degree program study the group of disciplines (in conformity with specialization): "Internet mass media as a media educational program", "Broadcasting projects in media education", "TV projects in media education", "Printed media as a media educational project". Special educational courses according to the discipline "Fundamentals of media competence" are established for students studying according to the program "Philology, specialization "National philology (Russian language and literature)" with fundamentals of media competence and the possibility to use this knowledge in education of school children.

Let us analyse the content of educational discipline "Up-to-date media educational technologies", the course "Up-to-date media educational technologies", has practically-oriented nature and results in creation of own project and its defence. In 2016 students who studied according to the Master's degree program performed their lessons devoted to media education on different sites: in schools, youth creative centres and in institutions of higher education in Chelyabinsk (https://jourcsu.ru/main/na-fakultete-zhurnalistikiprojjdet-nedelya-mediagramotnosti/;

https://vk.com/jourcsu?w=wall-768543_8272). The event was held as a part of Global week of media and information competence 2016 organized by UNESKO. From our point of view, the most outstanding projects are "Social media: the secret of safe communication" (for primary school) - V. Gornovaya, "Jointing of news" (students of the 2nd year of education of the specialty "Cinema and TV director") - E. Nadeikina; "Informational risks in social media, example based on BKontakte social media» (5-11 forms - active members of liceum) - N. Chramova;

"On the waves of cartoons" (for primary school) E. Shcherbinina; "Fundamentals of film creation" (11 form) - R. Klimova; "Creation and maintenance of VK group for all participants of educational process in school" (students of the 1st year of education, specialty "Teaching philologist") - E. Blokh and many others. We think that the topics offered by the students reflect the media educational approach. Besides on the stage of preparing of the project and its analysis the authors (students) paid attention to the following modern situation: generation $\mathrm{Z}$ - «on-line generation»: stable attention for 8 seconds, dominance of mosaic thinking [11]. The internal radar of this generation searches information that is worth the time spent of the information's search. To win their attention one should provide them with emotions that bring immediate profit and that are extremely exciting. This is why the main accent was made on visualization. But visual text should not only being created, it requires bright presentation. Our students are trained in both aspects. The classes of the students who study according to the Master's degree program are oriented on formation of skills for working with visual context including multimedia means of visualization.

When it comes to additional education we can say that this cluster is represented even more widely: YunGA+, contest for school and youth mass media since 2010 (in organization of face-to-face stage the work with teachers was presented by separate block), ImPRO, a contest of educational programs since 2012 (participants - heads of school and youth mass media and teacher performing media educational activity on the basis of educational (additional) disciplines; heads of children's and youth media educational projects and heads of media educational projects of institutions of higher education); publication of materials on information and analytical web portal MediaZavod since 2015 (http://mediazavod.ru/articles/daily/otraslevyetemy/mediaedu/); Annual scientific and practical conference "MEDIAEducation" in 2016; "SMIobshchestvo-obrazovaniye" ("Mass media - society education") traditional conference (once in 4 years) and others.

ImPRO (I am a media professional) - a contest of educational programs - a unique project that has no rivals on the territory of the Russian Federation. All the subjects of the Russian Federation and former Soviet Union republics have the right to take part in it (Regulation on the contest: https://vk.com/doc7858502 438813415?hash=c06dada6 $1 \mathrm{cfb} 999 \mathrm{fl} 4 \& \mathrm{dl}=0 \mathrm{fd} 2 \mathrm{~d} 4614825 \mathrm{cc} 41 \mathrm{cf}) . \quad$ Minsk (Belorussia), Tashkent (Uzbekistan), Moscow, Saint Petersburg, Novosibirsk, Ekaterinburg and many other took part in the contest in 2016.

According to the words of Olga Vassilyeva, Minister of education and science of the Russian Federation, in the conditions of global informatization the most important task is the preparation of young generation to comprehension of information that comes via multiple channels including mass media.

Modern heads of school mass media, teachers of the Russian language and literature, history and culture study do not possess the necessary level of media competence. And they are not able to prepare the young generation and help it to cope with real interaction with informational society that is full of deformation, aggression, negative feelings and thoughts and lie. The development of media and informational literacy (competence) in school will surely help generation $\mathrm{Z}$ that is unaware of real life out of 
the context of global informational environment, to work with information more carefully, more thoughtfully and be strong towards any informational provocation that comes either from internal Russian informational space or from international informational environment.

ImPRO contest appeals not only paying attention of society and professionals on the problem of media safety that is closely connected with insufficient level of mass media education, but also develop real practical measures aimed at the development of media education in Russia for young generation. Teachers present their educational programs on media competence (literacy) and media safety. The exchange of experience allows every participant to improve his qualification, to learn more about global trends in upbringing of young generation in the context of global informatization of the society.

Taking into account the thesis on the necessity of development of skills not only for creation but also for reading and understanding of visual information in the conditions of mass visualization of informational content, in 2016 the participants of onsite stage of ImPRO contest were asked to prepare for media educational class to the topic "Social media: trends of visualization of informational and communicative space"..

Except for only media educational tasks, the set of events offered by the faculty solves the problem of formation of scientific, educational skills among the young people-participants of the said events (students, schoolchildren, and teachers) and bears very high upbringing potential.

Let us explain it though explaining the said directions.

Scientific direction is aimed at involving of youth into scientific activity. It is implemented though preparation of term papers and graduation qualification thesis (for example: in 2017 the graduation qualification thesis to the topic "Formation of media competence among children and teen agers (on the basis of VLITSEYE88 press-center under Municipal budgetary educational institution Lyceum 88, Chelyabinsk)" - E.A. Blokh). In the process of writing works of this type, the author of the work studies the state of media competence among young generation, theoretical understanding of the problem takes place; effective ways of interaction are defined. As a rule students take part in scientific conferences where their works are judged. The conference "MEDIAEducation" became a very important additional component of working with media literacy in 2016. This conference anticipates the final stage of ImPRO contest and is aimed at theoretical understanding of issues and tasks of media education. Such up-to-date issues of contemporary media education as multimedia youth journalism, way and forms of presentation of media education, media education on the stage of pre-university education and many others have been considered during the conference. The materials of the conference have been published in "Sign: the problematic field of media education", the scientific magazine of the faculty of journalism and "Mediasreda 2017 (Media environment-2017)", the almanac of the faculty.

Educational direction is aimed at teaching the participant to work with informational flows - verbal and non-verbal. At this stage the most of attention is paid to collaboration with students of different specializations and teachers as a source of media literacy (competence). From a teacher to parent and child: round tables, seminars and master classes form Russian and international experts in the sphere of media and informational literacy (competence).

Upbringing direction is aimed at upbringing of citizens who are able to aware and understand modern informational flows and who are competent in the sphere of mass media.

\section{Conclusion}

In the conditions of mediatized society, the most up-todate issues are training of a person to competent comprehension and treatment of informational flow, the increasing of critical thinking, teaching a person methods of working with information, development and perfection of self-educating skills in the conditions of constantly changing media system. In the recent years the media consumption has changed. The contemporary audience prefers visual content. Therefore, it is necessary to change the model of media education. Semiotic model of media education that transfers focus on visual codes and grammar of media text and understanding of visual media language become the most appropriate in these conditions.

\section{References}

1. V. F. Oleshko, Media education: from theory to practice 119 (2008)

A. P. Korochenskiy, Media education and media competency: experts talk 58 (2009)

2. S. G. Korkonosenko, Media education and media competency: experts talk 49 (2009)

I. V. Zhilavskaya, Media and informational competence in Russia: way to future 56 (2014)

3. A. V. Fedorov, Media education: history and theory (Information for everybody, Moscow, 2015)

4. A.V. Onkovich, Media and informational competence in Russia: way to future 162, (2014)

5. I.A. Fateeva, Media education: theoretical basis and practical realization (Chelyabinsk State University, Chelyabinsk, 2007)

6. K.V Kiuru., E.E. Popova, Theory and Practice of Physical Culture 5, 9 (2016)

7. U. Eco, The Absent Structure: Introduction to Semiotics (Petropolis, St. Petersburg, 1998)

8. G.V. Mikhaleva,Media Education in Great Britain: Past and Present (South Federal University, Taganrog, 2015)

9. S.I. Simakova, Znak: The Problematic field of media education 2 (24), 107-118 (2017) 